\title{
VOC Sensing Devices with a Planar-type Structure based on YSZ and Modified Pt Electrode
}

\author{
Masami Mori ${ }^{1}$, Yoshihiko Sadaoka ${ }^{1}$, Shinichi Nakagawa ${ }^{2}$, Masahito Kida ${ }^{2}$, Takio Kojima ${ }^{2}$ \\ ${ }^{1}$ Department of Materials Science and Biotechnology, Graduate School of Science and Engineering, \\ Ehime University. Matsuyama, Ehime, 890-8577, Japan. \\ ${ }^{2}$ Future Products Project, New Product Planning \& Development Center, Engineering R\&D Group, \\ NGK Spark Plug Co., Ltd. Komaki, Aichi 485-8510, Japan.
}

\begin{abstract}
Potentiometric gas sensor with a planar-type structure was fabricated and applied to detect ethanol and toluene at sub-ppm levels. Electrode potential response to the VOC could be modified with the over-coating of Pt electrode with $\mathrm{MgAl}_{2} \mathrm{O}_{4}$ and/or Au. The coating induced the decrease in the activity of oxide ion at triple phase boundary of the sensing electrode. The potential responded to the concentration of the VOC and expressed as $E=a+b \log [\mathrm{C}]$. The characteristics, $a$ and $b$, depended on the thickness of over coated layer and it's material. The use of Au electrode induced the enhancements of the sensing behavior. Based on the mixed gases physisorption model, the observed potential response was discussed.
\end{abstract}

Key words: YSZ, ethanol, toluene, electrode potential, sensor

\section{INTRODUCTION}

Since air quality contamination by volatile organic compounds (VOCs), especially indoor, has become a serious problem for health in several scenes of human life. Therefore, continuous monitoring of VOCs is now strongly demanded, especially in urban spaces.

In this work, a planar-type potentiometric oxygen sensor with porous electrodes was fabricated and used to check the feasibility to detect sub-ppm levels of VOCs contaminating in air. To achieve a large signal and sensitivity for the planar-type sensor, at least, two directions could be considered, 1) over coating and/or mixing of the $\mathrm{Pt}$ electrode with new materials, 2) new electrode materials instead of Pt [1,2].

\section{RESULTS AND DISCUSSION \\ Effects of $\mathrm{MgAl}_{2} \mathrm{O}_{4}$ coating}

For the monolithic-type sensor with the porous $\mathrm{Pt}$ electrodes in which one-side electrode was covered with $\mathrm{MgAl}_{2} \mathrm{O}_{4}$, the $E M F$ level in uncontaminated air was very low and the observed electrode potential $(E)$ may be originated from the fabrication process. The observed low level potential suggested that the oxide ion concentration on the TPB sites was equilibrated to the oxygen concentration in gas and hardly influenced with the existence of the layer with $\mathrm{MgAl}_{2} \mathrm{O}_{4}$. The contaminations with VOC in $10 \mathrm{ppm}$ level induced the shift of the $E M F$ of about $100 \mathrm{mV}$. The $\mathrm{MgAl}_{2} \mathrm{O}_{4}$ layer was formed on the $\mathrm{Pt}$ electrode layer, while $\mathrm{MgAl}_{2} \mathrm{O}_{4}$ was directly connected to the YSZ at edges of the $\mathrm{Pt}$ electrode. It is reasonable to consider that the collision efficient of VOC to the TPB sites is decreased with the formation of the layer with $\mathrm{MgAl}_{2} \mathrm{O}_{4}$. If the adsorption of $\mathrm{VOC}$ is blocked with the layer, the level of the $E$ in the contaminated air is lower than that for the sensor with the bare Pt electrode. The catalytic activity of $\mathrm{MgAl}_{2} \mathrm{O}_{4}$ for $\mathrm{VOC}$ oxidation is clearly lower than that of $\mathrm{Pt}$. In the case of that the oxygen coverage of the porous layer with $\mathrm{MgAl}_{2} \mathrm{O}_{4}$ decreases with $\mathrm{VOC}$ adsorption and replacement of adsorbed oxygen with $\mathrm{VOC}$, the coverage of the adsorbed oxygen on the TPB should be equilibrated with the coverage of the oxygen on $\mathrm{MgAl}_{2} \mathrm{O}_{4}$ layer. Additionally, the halfcell potential for ethanol contamination was higher than that for toluene for the bare $\mathrm{Pt}$ electrode, while the reverse tendency was observed of the $\mathrm{Pt}$ electrode covered with $\mathrm{MgAl}_{2} \mathrm{O}_{4}$ layer. These confirmed results suggested that the activity of the oxide ion on the TPB sites are strongly influenced with the over coated layer. The large enhancement of the half-cell potential with VOC may be due to a large equilibrium constant of the adsorption isotherm of VOC on the porous layer.

\section{Effects of Au coating}

The surface morphology of Au-YSZ mixture formed on the Pt electrode was examined. It was obvious that the mixture is composed with finer Au particles and YSZ particles. From these observations, it is confirmed that the formed 
layer containing $\mathrm{Au}$ is well separated from the TPB sites formed in the interlayer with YSZ and $\mathrm{Pt}$ containing electrode layer. For the sensor with the $\mathrm{Pt}$ electrodes, the EMF at the uncontaminated air was smaller than about -30 $\mathrm{mV}$. A lower half-cell potential was detected and the level was not so high. The diffusion of the oxygen molecules was progressed in freely and not so disturbed by such layers formed on the Pt electrode.

The catalytic activity of Au surface is more less than that of $\mathrm{Pt}$ surface. The reaction of VOC with oxygen on the Pt electrode surface according to the $L-H$ mechanism and/or to the $E-R$ mechanism should be depressed by the over-coating of the Pt surface with Au. Also the adsorption of VOC on the surface of Au induced the decrease in the coverage of the oxygen molecules resulting the decrease in the oxygen concentration at around the TPB site. The dissociative adsorption of oxygen on the TPB also decreased. It should be noticed that even for the contaminated air with VOCs, the concentration of oxygen was approximated to $21 \%$ since the concentration of VOC (lower than $10 \mathrm{ppm}$ ) was extremely lower than that of oxygen in this study. The VOCs are directly adsorbed on the surface and oxidized on the surface of $\mathrm{Pt}$ electrode. The covering of the $\mathrm{Pt}$ electrode surface with $\mathrm{Au}$ induced a less oxidation of VOC due to the less catalytic activity of $\mathrm{Au}$. The VOC remained on the $\mathrm{Au}$ surface and induced the decrease in the surface density of the adsorbed oxygen originating from the replacements of adsorbed oxygen with VOC. The decrease in the surface density of the adsorbed oxygen resulted a decrease in the adsorbed oxygen on the TPBsites. The adsorbed VOC on the Au surface also diffused to inner layer and reacted with the adsorbed oxygen on the TPB-sites. Only the VOC passed through the Au layer and diffused to the TPB-sites reacted directly on the TPB surface with the dissociated oxygen resulting the electrochemical oxidation.
Table 1.

Sensing characteristics half cell $E=\mathbf{a}+\mathbf{b} \log (\mathrm{C})$ for ethanol and toluene

\begin{tabular}{|c|c|c|c|c|}
\hline & \multicolumn{2}{|c|}{ ethanol } & \multicolumn{2}{|c|}{ toluene } \\
\hline & a & b & a & b \\
\hline Pt & -0.0392 & -0.0541 & -0.0218 & -0.0387 \\
\hline $\begin{array}{l}\mathrm{MgAl}_{2} \mathrm{O}_{4} /(\mathrm{Pt} / \mathrm{YSZ}) \\
14 \mu \mathrm{m}\end{array}$ & -0.0427 & -0.0596 & -0.0255 & -0.0434 \\
\hline $72 \mu \mathrm{m}$ & -0.0513 & -0.0634 & -0.0271 & -0.0419 \\
\hline $104 \mu \mathrm{m}$ & -0.0437 & -0.0598 & -0.0259 & -0.0421 \\
\hline (Au/YSZ)(Pt/YSZ) & & & & \\
\hline $8.5 \mu \mathrm{m}$ & $-0.0142^{*}$ & $-0.0940^{*}$ & -0.0910 & -0.2569 \\
\hline $23 \mu \mathrm{m}$ & $-0.0553^{*}$ & $-0.0987^{*}$ & -0.0796 & -0.2340 \\
\hline $34 \mu \mathrm{m}$ & $-0.0599^{*}$ & $-0.0986^{*}$ & -0.0919 & -0.1859 \\
\hline $\mathrm{Au} /(\mathrm{Pt} / \mathrm{YSZ})$ & $-0.0725^{*}$ & $-0.1380^{*}$ & -0.105 & -0.1972 \\
\hline (Au/YSZ) & -0.1352 & -0.2139 & -0.2105 & -0.1241 \\
\hline
\end{tabular}

\section{CONCLUSIONS}

The effects of the contamination of ethanol and toluene at ppm levels on the EMF response of potentiometric oxygen sensors were investigated. The EMF responded to the concentration of the VOC and expressed as $E=$ $a+b \log [\mathrm{C}]$. The characteristics, $a$ and $b$, were depended on the thickness of the over coated layer and its material. The use of Au electrode instead of $\mathrm{Pt}$ electrode resulted the enhancements/improvements of the sensing behavior. Based on the mixed gases physisorption model, the observed nonNernstian relation was discussed. The activity of the oxide ion at the TPIB sites was distinctly decreased with the co-adsorption of the VOCs on the electrode surfaces. The observed high sensitivity to the VOC is originated from a higher equilibrium constant of VOC adsorption than that of oxygen adsorption.

\section{References}

[1] M.Mori, Y. Itagaki, Y.Sadaoka, Sensors and Actuators B (2011), in press.

[2] M.Mori, Y.Sadaoka, Sensors and Actuators B 146, 46-52 (2010). 